\title{
Análise do discurso das diretrizes curriculares nacionais de educação infantil: currículo como campo de disputas
}

\author{
Discourse analysis of Brazilian curriculum guidelines for early childhood education: \\ the curriculum as a field of disputes
}

\section{Análisis del discurso de las directrices curriculares nacionales para la educación infantil: currículo como campo de disputas}

\author{
RODRIGo SABALla DE CARVALHO*
}

\begin{abstract}
RESUMO - A partir dos Estudos Culturais em Educação e dos Estudos de Michel Foucault, pretende-se analisar os discursos das Diretrizes Curriculares Nacionais de Educação Infantil, de forma a evidenciar como estas instituem saberes que disciplinam, regulam e produzem sujeitos. Metodologicamente, é desenvolvida a análise do discurso, entendendo que as diretrizes prescrevem ações que objetivam o governamento docente. As análises são realizadas através de três unidades: condições de emergência das diretrizes; concepção de currículo; princípios, objetivos e eixos das propostas pedagógicas. Através das análises, conclui-se que as diretrizes reativam discursos redentores, reforçando a missão salvacionista atribuída historicamente às instituições de atendimento à infância.

Palavras-chave - Diretrizes curriculares. Educação infantil. Currículo. Discurso.
\end{abstract}

\begin{abstract}
Based on the Cultural Studies in Education and the Studies of Michel Foucault, we aim at analyzing the discourses of the Brazilian Curriculum Guidelines for Early Childhood Education, in order to show how they establish knowledge that discipline, regulate and produce subjects. Methodologically, discourse analysis is developed, understanding that the guidelines prescribe actions that aim at teacher's governance. The analyses are performed through three units: emergence conditions of the guidelines; curriculum design; principles, goals and pivots of the major pedagogical proposals. Through the analysis, we conclude that the guidelines reactivate redemptive discourses, reinforcing the Salvationist mission historically attributed to child care institutions.
\end{abstract}

Keywords - Curriculum guidelines. Early childhood education. Curriculum. Discourse.

RESUMEN - A partir de los Estudios Culturales en Educación y de los Estudios de Michel Foucault, se tiene como objetivo analizar los discursos de las Directrices Curriculares Nacionales para la Educación Infantil con el fin de evidenciar cómo estas instituyen saberes que disciplinan, regulan y producen sujetos. Metodológicamente, se desarrolla el análisis del discurso, al entender que las directrices prescriben las acciones que objetivan la gobernanza docente. Los análisis se llevan a cabo a través de tres unidades: las condiciones de emergencia de las directrices; concepción de currículo; principios, objetivos y ejes de las propuestas pedagógicas. A través de los análisis, se concluye que las directrices reactivan discursos redentores, reforzando la misión salvacionista históricamente atribuida a las instituciones de atención a la niñez.

Palabras clave - Directrices curriculares. Educación infantil. Currículo. Discurso.

\footnotetext{
* Doutor em Educação pela Universidade Federal do Rio Grande do Sul (Porto Alegre, RS, Brasil) e professor na Universidade Federal da Fronteira Sul (Erechim, RS, Brasil).E-mail: <rsaballa@terra.com.br>.
} 


\section{CONSIDERAÇõES INICIAIS}

Qualquer prática social não existe fora das palavras que se usam em cada época para descrevê-la (Ó, 2003, p. 9).

O reconhecimento teórico e legal da função social, política e pedagógica da Educação Infantil tornou-se um campo de disputas em que existem embates de discursos pela imposição de significados sobre qual é a concepção "adequada" de currículo para essa etapa de ensino. Conforme Silva (2002), o currículo é um espaço constante de luta em torno da significação e da identidade e, por essa razão, tem se constituído um território cultural "sujeito à disputa e à interpretação, no qual diferentes grupos tentam estabelecer sua hegemonia". Corroborando o argumento do autor, é possível dizer que o campo curricular opera como um potente meio de produção de discursos, criando verdades, interesses e conceitos, por meio dos quais torna suas orientações indelevelmente "naturais" e "necessárias" no contexto educacional.

A leitura das Diretrizes Curriculares Nacionais para a Educação Infantil - DCNEI (BRASIL, 2009) possibilita depreender que se procura, por meio do documento legal, promover e garantir a existência de um currículo que rompa com o assistencialismo, distancie-se da escolarização e seja promotor das relações das crianças consigo mesmas, com seus pares, com os adultos e com o mundo. Em tal perspectiva, nas diretrizes, palavras como aula, aluno, ensino, escola e conteúdo são interditadas no vocabulário curricular, por serem entendidas pelos especialistas da área (cujos estudos se sustentam na Sociologia da Infância e na Pedagogia Italiana) como integrantes de uma concepção escolarizante da infância.

Pesquisadores como Rocha (2001), Kramer (2009), Barbosa (2009), dentre outros, que compõem a comunidade epistêmica da área, preocupam-se com a reprodução das práticas do Ensino Fundamental na Educação Infantil. Essa preocupação deriva de dois fatores: a) a recente construção de uma Pedagogia da Infância como campo próprio de ação pedagógica; b) a constatação de que muitos profissionais, por não se sentirem habilitados para atuar com crianças na faixa etária de zero a cinco anos, mesmo sendo egressos de cursos de licenciatura em Pedagogia, ainda utilizam as práticas desenvolvidas nos anos iniciais do Ensino Fundamental como um modelo a ser seguido em sala de aula.

Em contrapartida, embora com menor visibilidade no cenário nacional, existem pesquisadores da área de Educação Infantil (influenciados pelas teorizações marxistas e pelos estudos de Vygotsky), como Arce (2004), Prado e Azevedo (2012), Martins e Arce (2010), que vêm tecendo uma crítica contundente ao que nomeiam processo de (des)escolarização da Educação Infantil e fetichização da infância. Esses autores reivindicam que a primeira etapa da Educação Básica também seja entendida do ponto de vista do conhecimento escolar a ser ensinado às crianças.

As colocações de ambos os grupos revelam que todo currículo, enquanto discurso disciplinador, inscrito na ordem do poder e do saber, sempre se encontra implicado no processo de constituição dos indivíduos. Por essa razão, a partir das contribuições do campo dos Estudos Culturais em Educação e dos Estudos de Michel Foucault, o objetivo do artigo é analisar os discursos legais presentes nas DCNEI (BRASIL, 2009) ${ }^{1}$, evidenciando o modo como essas diretrizes - que propõem orientações específicas para a educação das crianças de zero a cinco anos de idade (mesmo procurando se distanciar dos discursos dos pesquisadores que defendem a escolarização da Educação Infantil) - instituem saberes que procuram, entre outros aspectos, disciplinar, regular e "produzir" sujeitos de um determinado tipo Estes, sob a visível sustentação do campo da Pedagogia da Infância.

Tais colocações possibilitam afirmar, a partir de Silva (2002), que, independentemente da posição teórica assumida, não existe uma proposição curricular isenta de relações de poder, já que o currículo é um campo de produção e criação de significados que se encontra centralmente implicado naquilo que somos, naquilo que nos tornamos e naquilo que nos tornaremos. Popkewitz (2002) afirma que os discursos sobre educação construídos nas formulações das políticas curriculares não são apenas linguagens sobre a educação, mas parte de processos produtivos da sociedade, pelos quais os problemas são classificados, e as práticas, mobilizadas.

As proposições curriculares contêm em si não apenas informações, mas formas particulares de ver e sentir o mundo (nas quais podem ser incluídas as concepções de infância e de sua educação), configuradas nos modos como o conhecimento é organizado. Assim, esforços para organizar o conhecimento como currículo constituem modos de regulação social.

Sendo assim, cabe esclarecer o que são Diretrizes Curriculares. Estas podem ser entendidas como um conjunto de orientações, de parâmetros gerais curriculares, colocado para uma etapa educacional. O documento legal deve ter uma perspectiva plural, não se constituindo em um tratado educacional, nem explicitando uma opção por determinada linha teórica.

Embora sejam feitas ressalvas em relação a uma suposta perspectiva plural das diretrizes, é importante destacar que estas, como qualquer outra série enunciativa, apresentam lógicas específicas, afirmando seus próprios ordenamentos no detalhe. Ao definirem uma concepção 
de currículo, de proposta pedagógica, de princípios, eixos norteadores e objetivos que devem ser alcançados por meio das propostas, as diretrizes evidenciam claramente a precisão de suas fronteiras. Como aponta Palamidessi (2001), os ordenamentos curriculares apoiam-se em esquemas de causalidade linear, em redes causais de explicação baseadas no que se apresentam como condições necessárias, inevitáveis e determinantes para que a formação das crianças de zero a cinco anos se realize plenamente.

As diretrizes, por serem constituídas a partir de um conjunto de enunciados implicados em uma discursividade pedagógica oficial, não se operacionalizam por meio da repressão ou do constrangimento, mas através da produção permanente da subjetividade de todos os envolvidos. De acordo com Corazza (1995), os discursos dos documentos curriculares, embora tenham como foco principal as crianças, também difundem práticas para o docente exercitar posturas para seguir e maneiras de conduzir-se, tendo em vista seu exercício profissional. Isso ocorre porque a conduta docente é um efeito discursivo, uma vez que "o" sujeito professor ocupa posições, derivadas de combinações, composições e adaptações de discursos e práticas.

Pode-se dizer, então, que a proposição de orientações curriculares é uma das formas que as instituições estatais utilizam para regular, orientar, fixar limites e prescrever determinadas práticas e relações sociais no campo educativo. Por essa razão, o texto legal não é constituído por uma única voz ou por um conjunto de prescrições homogêneas. Mas, sim, por uma variedade de discursos produtores de relações de poder e saber que torna possível o domínio da subjetividade infantil, ao apresentar modos de nomear e entender as crianças, definindo modelos para conduzir a ação pedagógica a elas dirigida.

Segundo Ó (2003), existe uma "arte das distribuições", normalizando corpos e exercendo práticas de individualização através da cuidadosa distribuição dos saberes. Estes, ao ampliar a visibilidade sobre as crianças e sobre os docentes, os produz como sujeitos. As DCNEI orientam formas de perguntar, compreender e organizar o currículo, já que este é atravessado por definições históricas sobre o que deve ser conhecido e sobre o modo como devem ser reativados os objetos de conhecimento.

As orientações legais curriculares podem ser consideradas instâncias que classificam e ordenam um corpo de conhecimentos e ocupações escolares, não legislando nem funcionando por mando e obediência, mas através da distribuição e normalização a que dão forma e da circulação microfísica das relações de poder (CORAZZA, 1995, 2004). Assim, os ordenamentos legais que constituem as diretrizes também revelam o efeito dinâmico das rápidas mudanças que atravessam a cultura e o mundo contemporâneo. Isso ocorre porque inventam produtivos aparatos para a produção de verdades (indicações de práticas a serem desenvolvidas) e organizam sistemas de enunciados (uma ordem do discurso docente) que sustentam estratégias para levar a efeito as operações que se encarregam da produção das subjetividades infantis.

Na próxima seção, são expostos os aspectos metodológicos da pesquisa, bem como os conceitos a serem utilizados como ferramentas conceituais para a realização das análises.

\section{Perspectiva de ANÁlise: Metodologia, QUESTÕES DE PESQUISA E CONCEITOS}

A partir do referencial teórico foucaultiano, é desenvolvida uma análise do discurso das DCNEI, entendendo-as como um discurso pedagógico que organiza e articula modos de falar e de pensar e que, sobretudo, torna-se, no âmbito das instituições de Educação Infantil, um operador de distribuições - de indivíduos, de acontecimentos, de atividades e de enunciados, no espaço e no tempo. Isso significa que o discurso das diretrizes é evidenciado em seus processos de fabricação, criação, produção e divulgação de conhecimentos e verdades.

As diretrizes operam articulando jogos de poder e vontades de saber, estabelecendo vínculos entre um jogo de sedutoras proposições e a prescrição de uma série de ações possíveis que tem por objetivo produzir crianças e docentes de um determinado tipo, conforme assegura Palamidessi (2001) em sua pesquisa. Isso implica analisar tanto as relações de poder articuladas pelas DCNEI como os efeitos que os docentes são incitados a produzir sobre si mesmos por meio de suas práticas, de seus saberes, de seus discursos. Para tanto, serão desenvolvidas análises a partir das seguintes questões: a) Que prescrições (estratégias discursivas) são priorizadas para orientar a conduta dos docentes em relação à ação profissional na Educação Infantil?; b) De que maneira os discursos emergentes do documento legal promovem um determinado modo de significar o currículo e as práticas pedagógicas na Educação Infantil?

Conforme Foucault $(2005,2007)$, os discursos não são entendidos apenas como conjuntos de signos, mas enquanto práticas que formam sistematicamente os objetos dos quais tratam. Logo, para o autor, os discursos também podem ser considerados jogos estratégicos de ação e reação, de pergunta e de resposta, de dominação e de esquiva, como também de luta. Veiga-Neto (1996, p. 300) ressalta que "os discursos, por mais originais e livres que pareçam, jamais são simples produtos de insights ou de uma Razão suficiente; jamais eles resultam de atos de uma vontade soberana". 
Por isso, o conceito de discurso é entendido, no contexto das análises, em sua qualidade de constituidor daquilo que realmente se diz. Analisar as diretrizes sob essa perspectiva implica entendê-la como discurso legal que, sozinho, não tem efeitos. Antes disso, o que interessa é evidenciar de que forma as diretrizes obedecem a regras históricas, afirmam verdades desse tempo e conferem visibilidade às relações de poder e saber existentes no tecido social.

Assim, o foco analítico é centrado no papel dos discursos das DCNEI enquanto documento legal, problematizando a linguagem - o que é efetivamente dito em seus artigos - como enunciados constitutivos de determinados modos de entender as crianças, o currículo e as práticas desenvolvidas nas instituições. A intencionalidade das análises não é fazer interpretações reveladoras, mas capturar, no documento curricular, as regularidades sobre os sentidos que são atribuídos às crianças e aos docentes no texto legal.

Por essa via, também se deve destacar que as diretrizes operacionalizam práticas de governamento, já que estas, através de suas orientações, têm modificado a organização curricular da Educação Infantil no país e definido um modo de exercício docente - com seus vocabulários e práticas específicos. Em tal perspectiva, o conceito de governamento é visto, a partir de Foucault (2008), como qualquer modo mais ou menos calculado de direcionamento dos comportamentos ou das ações dos indivíduos. Nesse sentido, o processo de intervenção das diretrizes em relação ao currículo consiste em um amplo processo de orientação de condutas de professores, de acadêmicos, de instituições de Educação Infantil e da própria sociedade. $\mathrm{Na}$ qualidade de ferramenta metodológica, analisar os discursos das diretrizes sob a perspectiva do governamento é, de certo modo, aceder aos regimes de verdade que constituem os docentes de Educação Infantil na contemporaneidade.

As práticas de governamento operadas pelas DCNEI podem ser entendidas como ações de forças mais ou menos refletidas e calculadas que estruturam uma eventual maneira de atuação, à medida que exercem um tipo de poder que incita, estimula e impele os indivíduos a seguir uma determinada direção (DEAN, 1997). Através das orientações legais, crianças e docentes são descritos e expostos à intervenção e à regulação em um campo de governamento. Desse modo, é possível dizer, a partir de Foucault $(2004,2008)$ e Gordon (1991), que o governamento viabilizado nas diretrizes, por meio das orientações que prescrevem as orientações curriculares, constitui-se em uma forma de ação que objetiva guiar, moldar e transformar a conduta dos docentes. E, dessa maneira, torná-los sujeitos aptos a desenvolverem a prática pedagógica fundamentada na ordem do discurso das diretrizes curriculares.

Tais argumentos são posteriormente demonstrados, de modo sistemático, no decorrer das análises dos artigos $3^{\circ}$ ao $9^{02}$ do documento. É necessário esclarecer que as diretrizes, ao procurarem estruturar uma eventual maneira de atuação para os docentes, por meio de suas orientações, aproximam-se dos pressupostos da Pedagogia da Infância, dentre os quais se destacam: a) respeito à individualidade da criança; b) centralidade da criança no planejamento; c) ênfase nos interesses e necessidades da criança; d) criação de espaços em que as crianças possam produzir culturas infantis; e) assunção do processo de aprendizagem em detrimento ao ensino; f) renovação do repertório vocabular pedagógico; g) orientação dos docentes e suas consciências nos caminhos que conduzem ao progresso, à verdade, à emancipação e à salvação, tendo em vista o desenvolvimento integral das crianças. Assim, a análise do discurso das DCNEI é extremamente importante para que se possam entender as práticas que estas instituem, pois, conforme aponta Ó (2003, p. 83):

[...] são os vocabulários comuns, as orientações teóricas, as posições normativas e as formas de explicação que ajudam a estabelecer as formas de coordenação e associação entre indivíduos, grupos e organizações. Constrói-se um aparato conceptual capaz de circunscrever problemas sociais, indicando medidas para sua gestão eficaz e de identificar os problemas de foro interno dos indivíduos para os transformar em assuntos públicos.

Portanto, é necessário esclarecer que, para contemplar a problematização proposta, as análises são desenvolvidas a partir de três unidades analíticas. Inicialmente, são apresentadas as condições de emergência das diretrizes, destacando os documentos que as antecederam. Em seguida, o foco é a concepção de currículo expressa no documento legal e seus efeitos, no que diz respeito ao trabalho docente. Prosseguindo a problematização das orientações curriculares, são destacados os princípios, os objetivos e os eixos norteadores das propostas pedagógicas. Por fim, nas considerações finais, são retomadas as principais discussões desenvolvidas, elucidando os modos como as DCNEI operam na constituição de docentes e crianças na contemporaneidade.

\section{CONDIÇÕES DE EMERGÊNCIA DAS DCNEI}

Traçar as condições de emergência das DCNEI supõe mostrar como o documento foi gestado nas tramas discursivas e nas relações político-institucionais que têm permeado o campo das políticas de Educação Infantil 
no Brasil, a partir da década de 1980. As concepções teóricas e a legislação específica em relação aos direitos das crianças foram sendo modificadas a partir das últimas décadas do século XX. A Educação Infantil deixou de ter como referência as políticas de assistência, recreação e saúde e passou a ser tratada como um tema educacional. E a criança tornou-se o centro do processo educativo, tendo direito à educação formal.

De acordo com Kramer (2009), nesse contexto, a Constituição Federal (CF) de 1988 foi um marco legal importante para a garantia da Educação Infantil enquanto direito das crianças e de suas famílias. Em 1990, como consequência de um longo processo que articulou o Estado e as entidades da sociedade civil organizada, foi homologado o Estatuto da Criança e do Adolescente (ECA - Lei 8.069/90), que reforçou o direito constituinte da criança pequena à educação. Em seu artigo 54, inciso IV, o ECA fortaleceu o que estava previsto na CF/1988, ratificando que creches e pré-escolas eram direitos das crianças.

A partir de então, teve início a publicação de programas de documentos oficiais relativos à situação da Educação Infantil. Em 1994, foi estabelecida pela primeira vez uma Política Nacional de Educação Infantil. As proposições de tal política enfatizaram a preocupação com o desenvolvimento de propostas curriculares específicas para as crianças em creches e pré-escolas e definiram que o currículo da Educação Infantil deveria ter como referência o nível de desenvolvimento das crianças, a diversidade social e cultural e os conhecimentos que se pretendia universalizar.

O debate sobre a elaboração de propostas pedagógicas para o desenvolvimento do trabalho na Educação Infantil intensificou-se a partir do ano seguinte. A Coordenação da Educação MEC/Coedi realizou um diagnóstico das propostas pedagógicas em curso naquela época, nas cidades brasileiras. O trabalho foi iniciado por uma equipe de especialistas na área, a partir de uma discussão conceitual sobre o que seria currículo ou proposta pedagógica na Educação Infantil. A discussão foi desencadeada a partir da análise de textos produzidos pelas próprias consultoras que compunham a equipe: Tisuko Morchida Kishimoto, Zilma de Moraes Ramos de Oliveira, Maria Lúcia Machado, Ana Maria Mello e Sônia Kramer.

Por meio da consultoria com as professoras citadas, foram publicados dois documentos que marcaram efetivamente o início da operacionalização de uma política curricular para a Educação Infantil no país: 1) Propostas pedagógicas e currículo na Educação Infantil: um diagnóstico e a construção de uma metodologia de análise (MINISTÉRIO DA EDUCAÇÃO E DO DESPORTO, 1996); 2) Critérios para um atendimento em creches que respeitem os direitos fundamentais das crianças (MINISTÉRIO DA EDUCAÇÃO, 1997).

O primeiro documento abordou a conceitualização e a definição das funções de um currículo para a educação de crianças em creches e pré-escolas e destacou a necessidade de serem elaboradas propostas curriculares para a Educação Infantil. Porém, cabe destacar que não houve consenso entre as autoras do documento em questão quanto ao uso do termo currículo. Kramer, por exemplo, não estabeleceu nenhuma diferenciação entre currículo e proposta pedagógica, mas expressou claramente a sua preferência ao abordar o segundo em suas proposições. Oliveira não diferenciou os termos e optou pelo uso conceitual de currículo em sua argumentação. Kishimoto, por sua vez, estabeleceu uma diferenciação entre currículo e proposta pedagógica. A autora afirmou que currículo é algo mais específico (o que será ensinado) e que proposta pedagógica é o documento que contempla as concepções de escola, ensino e aprendizagem, apresentando uma maior amplitude. Desse modo, optou pela utilização de currículo em seu texto, afirmando que este deve abranger conceitos, princípios, procedimentos, atitudes e formas de avaliação. Por outro lado, Mello e Machado realizam diferenciações entre currículo e proposta pedagógica, preferindo a utilização do segundo, por considerarem seu uso mais adequado à Educação Infantil. Mello utilizou o termo proposta psicopedagógica, e Machado propôs o uso de projeto educacional pedagógico em vez de currículo. Por outro lado, o documento Critérios para um atendimento em creches que respeitem os direitos fundamentais das crianças (MINISTÉRIO DA EDUCAÇÃO, 1997) apresentou um caráter mais abrangente, definindo que as crianças nas instituições de Educação Infantil deveriam ter direito à brincadeira, a um ambiente aconchegante, seguro e estimulante, à atenção individualizada, à proteção e ao afeto.

As discussões propostas pelas especialistas nos documentos em questão podem ser entendidas enquanto imperativos pedagógicos que conferiram visibilidade aos sujeitos (crianças, docentes, gestores), definindo o que podia ser dito (e quem poderia dizê-lo) e, sobretudo, determinando o que era permitido e o que deveria ser excluído do vocabulário. Tal visão acentua o caráter constitutivo e produtivo do currículo no processo de produção de subjetividades. Mais do que orientar a organização de propostas curriculares através da mediação de saberes e práticas, as orientações das especialistas engendraram saberes capazes de constituir crianças e docentes como sujeitos pedagógicos morais.

Conforme Aquino e Vasconcellos (2012), esse movimento de discussão e proposição de orientações para a elaboração de propostas pedagógicas nas instituições foi caracterizado naquele contexto por seu caráter 
"democrático" de consulta às redes de ensino e aos pesquisadores da área. Os documentos citados fizeram parte do debate nacional em torno da elaboração da Lei de Diretrizes e Bases da Educação Nacional (Lei 9.394/96), que consolidou a inclusão de creches e préescolas nos sistemas de ensino, tornando efetivamente legal as principais diretrizes apontadas pela Política Nacional de Educação Infantil (BRASIL, 2005). A partir da homologação da lei, iniciou-se no país um período de transição das instituições de Educação Infantil das Secretarias de Assistência Social para as Secretarias de Educação, objetivando que fossem atendidas as normativas presentes na nova legislação.

Em 1998, foram então publicados e distribuídos os Subsídios para credenciamento e funcionamento de Instituições de Educação Infantil. O documento tinha como objetivo orientar a elaboração, a execução e a avaliação de propostas pedagógicas. Além disso, assegurou que as propostas pedagógicas, a partir daquele momento, seriam consideradas requisito indispensável para o funcionamento das instituições.

Mesmo diante do trabalho realizado pela equipe de assessoria na elaboração das propostas curriculares para a Educação Infantil, o Ministério da Educação e Cultura (MEC), ainda no ano de 1998, apresentou um currículo nacional para esse nível de ensino através da publicação do Referencial Curricular Nacional para a Educação Infantil (RCNEI), como integrante da série de Parâmetros Curriculares Nacionais (PCN) publicada para o Ensino Fundamental e Médio no mesmo período.

Antes de ser publicado, o RCNEI sofreu muitas críticas de especialistas da área da Educação Infantil, que escreveram pareceres não favoráveis à publicação do documento. O MEC reelaborou algumas questões do referencial a partir dos pareceres dos especialistas consultados e o publicou com a aprovação do Conselho Nacional de Educação (CNE), que o definiu como orientações de caráter não obrigatório.

Após a divulgação do referencial, o MEC encerrou, conforme apontam Nogueira e Alves (2012), as discussões sobre a elaboração das propostas curriculares para a Educação Infantil. A atitude do governo corroborou o entendimento de que o RCNEI seria "a" proposta curricular nacional a ser seguida por todas as instituições, embora não tivesse caráter obrigatório. No final do ano de 1998, o CNE aprovou o Parecer CEB 22/98, que apresentou as Diretrizes Curriculares Nacionais para a Educação Infantil (DCNEI), e, em 7 de abril de 1999, aprovou a resolução que as instituiu com o objetivo de nortear, em caráter obrigatório, o processo de organização das propostas pedagógicas das instituições de Educação Infantil.

Prosseguindo com as orientações legais, a partir de 2001, por meio do Plano Nacional de Educação (PNE), o MEC publicou um conjunto de documentos que tinha como objetivo orientar os estados e municípios no desenvolvimento de políticas públicas, com vistas ao alcance da qualidade no atendimento às crianças pequenas. Os documentos publicados foram os seguintes: 1) Política Nacional de Educação Infantil: pelo direito das crianças de zero a seis anos à educação (BRASIL, 2005); 2) Parâmetros Nacionais de Qualidade para a Educação Infantil (BRASIL, 2006); 3) Indicadores da Qualidade na Educação Infantil (MINISTÉRIO DA EDUCAÇÃO, 2009b). O conjunto de documentos apresentados retomou e ampliou os princípios defendidos na Política Nacional de Educação Infantil de 1994.

No âmbito do Programa Currículo em Movimento (SEB/MEC), também foram produzidos por especialistas da área outros documentos endereçados à Educação Infantil: 1) Práticas cotidianas na Educação Infantil: bases para a reflexão sobre as orientações curriculares (BARBOSA, 2009); 2) Subsidios para Diretrizes Curriculares para Educação Básica: Diretrizes Curriculares Nacionais Especificas para Educação Infantil (KRAMER, 2009).

Além desses documentos, também foram elaboradas as novas Diretrizes Curriculares Nacionais para a Educação Infantil, aprovadas pela Resolução CNE/ CEB no 5/2009. Esta instituiu as novas DCNEI a serem observadas na organização das propostas pedagógicas das instituições de Educação Infantil brasileiras, revogando as diretrizes aprovadas dez anos antes. O objetivo da homologação das novas DCNEI foi orientar as instituições de Educação Infantil no planejamento de suas propostas curriculares, apontando um conjunto de princípios defendidos pelos diversos segmentos ouvidos no processo de sua elaboração. Assim, as diretrizes retomaram os princípios éticos, políticos e estéticos que haviam sido definidos na resolução anterior, estabelecendo como eixos norteadores do currículo as interações e as brincadeiras, como podeser acompanhado nas análises apresentadas na próxima seção.

\section{O CURRÍCULO NAS DCNEI}

Art. 3ํ O currículo da Educação Infantil é concebido como um conjunto de práticas que buscam articular as experiências e os saberes das crianças com os conhecimentos que fazem parte do patrimônio cultural, artístico, ambiental, científico e tecnológico, de modo a promover o desenvolvimento integral de crianças de 0 a 5 anos de idade.

Art. 4ํ As propostas pedagógicas da Educação Infantil deverão considerar que a criança, centro do planejamento curricular, é sujeito histórico e de direitos que, nas interações, relações e práticas cotidianas que vivencia, constrói sua identidade pessoal e coletiva, 
brinca, imagina, fantasia, deseja, aprende, observa, experimenta, narra, questiona e constrói sentidos sobre a natureza e a sociedade, produzindo cultura.

Art. 5o A Educação Infantil, primeira etapa da Educação Básica, é oferecida em creches e pré-escolas, as quais se caracterizam como espaços institucionais não domésticos que constituem estabelecimentos educacionais públicos ou privados que educam e cuidam de crianças de 0 a 5 anos de idade no período diurno, em jornada integral ou parcial, regulados e supervisionados por órgão competente do sistema de ensino e submetidos a controle social (MINISTÉRIO DA EDUCAÇÃO, 2009a).

O currículo, compreendido como conjunto de práticas; a criança vista como centro do planejamento e produtora de culturas infantis; a promoção do desenvolvimento integral das crianças pautada por meio de uma educação baseada em brincadeiras, imaginação, fantasia e desejo; os saberes e experiências das crianças articulados com os conhecimentos que fazem parte do patrimônio cultural, artístico, ambiental, científico e tecnológico da sociedade; e a aprendizagem considerada como vetor da ação pedagógica são todos modos de conceber o currículo na Educação Infantil. O que ocorre a partir da constituição de um vocabulário específico, em que os saberes, os interesses e as necessidades das crianças assumem o primeiro plano da ação pedagógica.

A homologação das DCNEI foi um modo encontrado de normatizar as orientações curriculares. Barbosa (2009), a partir de uma pesquisa em que analisou as propostas pedagógicas das instituições de educação no país, identificou uma variedade de modos de significar o currículo. A autora constatou a existência de instituições que trabalham com um currículo centrado em áreas de conhecimento (língua portuguesa, matemática, ciências naturais, etc.), centrado somente em brincadeiras. E, ainda, um grande número de instituições que fazem uso de um currículo baseado em datas comemorativas, sob a alcunha de projetos pedagógicos, nas quais são desenvolvidas atividades variadas, sem propósitos claros e significativos para as crianças.

Conforme apontam Aquino e Vasconcellos (2012), o conceito de currículo expresso nas diretrizes não é pautado no conhecimento disciplinar e escolar, pois é considerado como um conjunto de práticas que possibilita que os docentes elaborem, de modo autônomo, os seus planejamentos, a partir das experiências e dos interesses das crianças, tendo em vista as relações, as brincadeiras e a promoção das culturas infantis.

Canavieira (2012, p. 43) afirma que o conceito de currículo expresso nas orientações curriculares "propiciou certo avanço na superação de algumas polêmicas dentro da área, tais como o peso do viés da psicologia cognitivista, o entendimento de formação de leitores e escritores na primeira infância e, principalmente, a importância das interações infantis no processo educativo". Para a autora, o desafio proposto para que as instituições de Educação Infantil desenvolvam suas práticas pedagógicas, tendo como eixos norteadores do currículo as interações e as brincadeiras, pode ser considerado um avanço político, pedagógico e epistemológico. Tais definições evidenciam a centralidade que as relações estabelecidas entre as crianças deve ter no processo educativo. Porém, ela também ressalta que a compreensão teórica desse novo modo de conceber o currículo não tem sido fácil para os docentes que atuam na Educação Infantil, pois, além da falta de formação inicial e continuada, não há espaços adequados e materiais que possibilitem o desenvolvimento do trabalho pedagógico com as crianças.

Contrariando a perspectiva apresentada, Prado e Azevedo (2012) ressaltam que os defensores do currículo expresso nas diretrizes, por assumirem os pressupostos da Pedagogia da Infância, estão advogando a "não escolarização" por meio de um currículo apenas como conjunto de práticas. Defesa que ocorre em razão de conceituarem o termo escolarização como um processo de ensino meramente transmissivo, ligado à forma como os escolanovistas a concebiam. A concepção das autoras aponta para o entendimento da "escolarização" da criança como um processo educativo que tem início com sua entrada na instituição escolar, independentemente de sua idade, e que, portanto, não se limita ao ensino de conteúdos escolares.

Ratificando a crítica das referidas autoras, Arce (2004, p. 156), de modo contundente, declara que o movimento da Pedagogia da Infância corta definitivamente todos os laços com o ensino e com a figura do professor como alguém que transmite conhecimento às crianças. A autora afirma que as crianças estão sendo naturalizadas pelos docentes como detentoras do saber, da bondade e da solidariedade humana, remontando às concepções educacionais de Froebel - o criador dos jardins de infância. Arce também questiona se é possível existir educação sem ensino e o que diferenciaria as instituições de Educação Infantil de outros espaços não escolares, como clubes, parques, playgrounds e praças, onde as crianças também brincam e interagem com os seus pares.

A partir dessa exposição, cabe destacar a arena de embates na qual tem sido travada uma disputa em relação aos modos de significar o currículo na Educação Infantil. Percebe-se o caráter ordenador e disciplinador do currículo, no qual são operacionalizadas certas disposições, modos de pensar, classificar e hierarquizar o que deve ser conhecido, tendo em vista a produção de subjetividades.

Em uma perspectiva foucaultiana, a subjetividade é completamente produzida em diferentes práticas 
discursivas, em relações heterogêneas de poder-saber. Essa subjetividade demandada pelo discurso das diretrizes disputa espaço com demandas de outros textos, os quais, por sua vez, também divulgam outros modos de entender a criança, a educação, o docente e o currículo.

Conforme Corazza (2004), o currículo é constituído por definições históricas sobre o que deve ser conhecido, que classificam e ordenam o corpo de conhecimentos, e sobre as ocupações escolares. Por essa via, ao se entender o currículo em relação imanente com as tecnologias de poder, é possível problematizá-lo conforme a referida autora: na sua condição de discurso pedagógico que organiza, articula e coloca em ação determinados modos de falar e de pensar, tornando-se um operador de distribuições de indivíduos, de acontecimentos e de atividades no espaço e no tempo.

As orientações curriculares procuram produzir certos tipos de indivíduos que delas passam a fazer parte, salienta Corazza (1995). O currículo expresso nas diretrizes está implicado na produção de subjetividades e na constituição de modos de existência. Isso ocorre à medida que as diretrizes prescrevem modos de ser $\mathrm{e}$ divulgam uma série de práticas que sugere como os indivíduos devem se portar, constatando que o currículo opera no governamento dos indivíduos.

Pode-se depreender, então, que não existe $o$ sujeito ( $a$ criança, $o$ docente de Educação Infantil), mas a produção de subjetividades. O sujeito do discurso não é individual, mas uma posição que se ocupa em relação aos objetos de que trata. Esse entendimento está ancorado na noção de sujeito desenvolvida pelo pensamento pósestruturalista, o qual, de acordo com Silva (2002), rejeita o entendimento do sujeito como sendo fixo, unitário, estável, transcendente, dotado de uma racionalidade objetiva e de uma essência universal.

Tomando como exemplo a produção da subjetividade docente a partir das orientações curriculares em análise, Prado e Azevedo (2012, p. 49) ressaltam que o docente é entendido no âmbito do documento curricular como mero protetor dos direitos da infância, que acompanha as crianças em um espaço de vivência, "um lugar protegido no qual as crianças estão protegidas das mazelas do mundo adulto". Isso remete à compreensão de que o discurso curricular é constituído por um conjunto de estratégias através das quais o poder, continuamente, investe em práticas de governo - normativo, regulatório e prescritivo -, que funcionam como (ou fazem funcionar) práticas de governamento.

Prosseguindo as análises, na próxima seção são discutidos os princípios, os objetivos e os eixos norteadores descritos pelas DCNEI como orientação para o planejamento das propostas pedagógicas.

\section{PrincípIOS, OBJETIVOS E EIXOS NORTEADORES DAS PROPOSTAS PEDAGÓGICAS}

Art. 6ํㅡㄹ As propostas pedagógicas de Educação Infantil devem respeitar os seguintes princípios:

I - Éticos: da autonomia, da responsabilidade, da solidariedade e do respeito ao bem comum, ao meio ambiente e às diferentes culturas, identidades e singularidades.

II - Políticos: dos direitos de cidadania, do exercício da criticidade e do respeito à ordem democrática.

III - Estéticos: da sensibilidade, da criatividade, da ludicidade e da liberdade de expressão nas diferentes manifestações artísticas e culturais.

Art. 7o $\mathrm{Na}$ observância destas Diretrizes, a proposta pedagógica das instituições de Educação Infantil deve garantir que elas cumpram plenamente sua função sociopolítica e pedagógica:

I - oferecendo condições e recursos para que as crianças usufruam seus direitos civis, humanos e sociais;

II - assumindo a responsabilidade de compartilhar e complementar a educação e cuidado das crianças com as famílias;

III - possibilitando tanto a convivência entre crianças e entre adultos e crianças quanto à ampliação de saberes e conhecimentos de diferentes naturezas;

IV - promovendo a igualdade de oportunidades educacionais entre as crianças de diferentes classes sociais no que se refere ao acesso a bens culturais e às possibilidades de vivência da infância;

$\mathrm{V}$ - construindo novas formas de sociabilidade e de subjetividade comprometidas com a ludicidade, a democracia, a sustentabilidade do planeta e com o rompimento de relações de dominação etária, socioeconômica, étnico-racial, de gênero regional, linguística e religiosa.

Art. $8^{\circ}$ A proposta pedagógica das instituições de Educação Infantil deve ter como objetivo garantir à criança acesso a processos de apropriação, renovação e articulação de conhecimentos e aprendizagens de diferentes linguagens, assim como o direito à proteção, à saúde, à liberdade, à confiança, ao respeito, à dignidade, à brincadeira, à convivência e à interação com outras crianças.

Art. 9o As práticas pedagógicas que compõem a proposta curricular da Educação Infantil devem ter como eixos norteadores as interações e a brincadeira [...] (MINISTÉRIO DA EDUCAÇÃO, 2009a).

A partir da leitura desses artigos, são realizadas duas considerações analíticas. A primeira diz respeito à maneira como os artigos em questão apresentam um vocabulário que instrui o docente sobre os modos como deve ser configurada a proposta pedagógica nas instituições de Educação Infantil. 
O uso da palavra deve, nos artigos 6으, 70 e 8oㅡ, é exemplar por evidenciar o caráter prescritivo das diretrizes. As propostas pedagógicas devem respeitar, devem garantir e devem ter como objetivo. O uso aparentemente natural do vocábulo em questão denota que, embora

sejam significadas pelo seu caráter plural e flexível, as diretrizes apresentam fronteiras muito precisas. Os vocabulários utilizados jamais são neutros, pois exercem um estrito controle sobre aquilo que pode ser dito ou não no campo da educação (Ó, 2003). Essa é a ordem do discurso que permite aos seus enunciados se inscreverem em determinado horizonte teórico ao definirem o que pertence a esse campo e os limites entre proposições verdadeiras e falsas. Ao apresentar como devem ser elaboradas as propostas pedagógicas, o documento apresenta maneiras específicas de significar a criança, a aprendizagem e o currículo.

As orientações presentes nos artigos em que são enfatizados os princípios das propostas pedagógicas podem ser entendidas como uma espécie de "pastorado das consciências e do bem agir", que têm efeitos disciplinares sobre a conduta dos indivíduos. Esse pastorado, conforme Gordon (1991), pretende a redenção e a conversão dos indivíduos em sujeitos esclarecidos, autorreflexivos e participativos na construção de uma sociedade que se pretende igualitária, emancipada e democrática. Para a operacionalização do pastorado das consciências, é imprescindível que o docente se sinta impelido a assumir o papel de intelectual crítico, reflexivo, abnegado e comprometido com a "salvação" das crianças por meio da educação. Tal intelectual atua como mentor, guiando a conduta de todos (e de cada um), provendo as carências de seu rebanho (através de sua "visão de mundo" e criticidade), como um conselheiro e pastor que estimula a participação e zela pelo cuidado e pela educação dos seus.

Nesse sentido, de acordo com Foucault (2004), o poder pastoral pode ser considerado, entre outros aspectos, uma forma de governamento que teve suas condições de emergência nas instituições cristãs. Enquanto forma de racionalidade política, foi a pastoral cristã que disseminou o comportamento da pessoa autorreflexiva, extremamente valorizada pelos teóricos críticos, através de uma pedagogia de subjetivação moral que se encontra no centro da escolarização moderna e ressoa de modo exemplar no texto das DCNEI. O foco do trabalho das propostas pedagógicas presentes no contexto da orientação legal é direcionado à ampliação de conhecimentos e saberes promotores de igualdade de oportunidades educacionais às crianças enquanto sujeitos de direitos.

Prosseguindo a análise, a segunda consideração se relaciona à flexibilidade curricular presente no documento, no qual existe um suposto espaço para os docentes pensarem como realizar a seleção e a articulação das linguagens a serem trabalhadas com as crianças. Tomando como eixos norteadores as interações e as brincadeiras, a proposta pedagógica é apresentada nas diretrizes como sendo o modo institucional de operacionalização do currículo pelos docentes, como se estes fossem conhecedores do vocabulário empregado e das concepções teóricas subjacentes ao texto legal.

Conforme sustenta Veiga-Neto (1996), mesmo que a flexibilidade curricular seja entendida como um atributo positivo à medida que se torna cada vez mais capaz de se adaptar às rápidas mudanças que ocorrem no mundo social, não se pode esquecer que, quanto mais flexível é o currículo, menor é a autonomia docente Isso porque esta modela os modos de pensar o currículo pelos conhecimentos que torna disponível e, sobretudo, pelas habilidades que consegue "implantar" naqueles que por ela são envolvidos.

Assim, tendo em vista o encaminhamento das reflexões finais, são discutidos na próxima seção alguns efeitos das DCNEI no processo de produção de crianças e docentes.

\section{CONSIDERAÇÕES FINAIS}

Pelo que foi acentuado no decorrer do artigo, podese dizer que o discurso das diretrizes constrói a realidade pelo campo de possibilidades que ativa. Governa, também, a realidade à medida que, por exemplo, as crianças são vistas como seres produtores de cultura que devem aprender a partir de múltiplas linguagens (por meio das interações e brincadeiras), e o professor, como um mediador da aprendizagem, e não do ensino.

$\mathrm{O}$ valor de verdade atribuído a essas enunciações faz do discurso das diretrizes uma prática efetiva. Tal atribuição impõe uma demanda ao campo da educação, determinando que diversos mecanismos pedagógicos sejam ativados, favorecendo determinadas situações e impossibilitando outras.

As orientações curriculares estão centralmente envolvidas na produção de subjetividades e na constituição de modos de existência (SILVA, 2004). Por essa razão, a problematização das DCNEI possibilitou a desconstrução do texto legal enquanto objeto aparentemente "estável" e "natural", revelando que este atua na subjetivação docente à medida que prescreve e divulga uma série de práticas, técnicas e estratégias que sugerem como os indivíduos devem atuar.

Assim, nas análises apresentadas, foi possível salientar o caráter produtivo do documento, destacando que, através da linguagem, constituem-se os sentidos que são atribuídos ao currículo na Educação Infantil. Partindo dessa perspectiva, não existe um "objeto natural" chamado currículo, pois somente ao ser objetivado como tal, através 
da produção de discursos, este passa a se materializar. Logo, conforme destaca Palamidessi (2001), através das diretrizes e da proposição de um currículo, constitui-se discursivamente um determinado modo de conceber o conhecimento, a criança e o docente de Educação Infantil.

Também foram apresentadas as condições de produção das diretrizes e discutidos os modos como têm sido significados o currículo e as práticas pedagógicas no documento enquanto estratégias de governamento diretamente implicadas na produção de um docente que esteja apto a operacionalizar os pressupostos apresentados nas orientações curriculares. O objetivo das discussões desenvolvidas não foi procurar nas DCNEI o currículo em sua materialidade, mas salientar as práticas discursivas que o constituem. Foi possível, então, perceber que as prescrições presentes nas diretrizes podem operar formas de governamento por meio de "imperativos pedagógicos" fundamentados na Pedagogia da Infância. Já que esta confere visibilidade às crianças enquanto seres naturais, define o que pode ser dito (e quem pode dizê-lo) e, sobretudo, determina o que é permitido e o que deve ser excluído no discurso pedagógico docente.

A produção discursiva das diretrizes expressa claramente um processo de redenção e salvacionismo por meio da formação "integral” da criança. Ó (2003) ratifica tal assertiva ao afirmar que as ciências pedagógicas colocam em destaque uma cultura da redenção, as quais, através dos discursos de salvação, tornam a criança um indivíduo que, com atenção e cuidado, pode ser salvo. Esse processo, é claro, tem contribuído na produção de novos sujeitos.

Ainda é cedo para se analisar os efeitos políticos desse processo. Mas é certo que os profissionais da área precisam estar atentos, pois, mais do que orientar o planejamento das práticas pedagógicas desenvolvidas e a mediação da aprendizagem por meio de interações e brincadeiras, as diretrizes engendram saberes capazes de constituir a criança e, de modo correlato, o próprio docente da Educação Infantil. Assim, é possível dizer que as diretrizes reativam discursos "redentores" para designar que, através do trabalho docente e da escola enquanto grande instituição moderna responsável pela construção da cidadania, os problemas educacionais da Educação Infantil podem ser combatidos. O que reforça a "missão salvacionista" atribuída historicamente às instituições de atendimento à infância.

Logo, o que pode ser feito diante das discussões apresentadas no decorrer do artigo? A partir do entendimento do currículo como espaço ordenador e disciplinador, através do qual circulam discursos que lutam para impor seus significados, é possível entender, a partir de Popkewitz (2002), que, através de orientações curriculares, como as DCNEI, existe a inscrição de sistemas simbólicos que orientam formas de os docentes atuarem com as crianças. Por essa razão, é imprescindível que estes estejam atentos às orientações curriculares, questionando o modo como estas funcionam, produzem as crianças e os produzem enquanto profissionais no tempo presente.

\section{REFERÊNCIAS}

AQUINO, Ligia Maria Leão; VASCONCELLOS, Vera Maria. Questões curriculares para Educação Infantil e PNE. In: FARIA, Ana Lucia Goulart; AQUINO, Ligia Maria Leão. Educação Infantil e PNE: questões e tensões para o século XXI. Campinas: Autores Associados, 2012. p. 69-82.

ARCE, Alessandra. Pedagogia da Infância ou fetichismo da infância? In: DUARTE, Newton (Org.). Crítica ao fetichismo da individualidade. Campinas: Autores Associados, 2004. p. 146-168.

BARBOSA, Maria Carmem Silveira. Práticas cotidianas na Educação Infantil: bases para reflexão sobre as orientações curriculares. Projeto de Cooperação Técnica MEC e UFRGS para construção de orientações curriculares para a Educação Infantil. Brasília, 2009.

BRASIL. Constituição (1988). Constituição da República Federativa do Brasil. Brasília, DF: Senado, 1988.

BRASIL. Lei no. 8.069, de 13 de julho de 1990. Dispõe sobre o Estatuto da Criança e do Adolescente e dá outras providências. Diário Oficial da União, Brasília, DF, 16 jul. 1990.

BRASIL. Lei no . 9.394, de 20 de dezembro de 1996. Estabelece as diretrizes e bases da educação nacional. Diário Oficial da União, Brasília, DF, 23 dez. 1996.

BRASIL. Lei $n^{\circ} 10.172$, de 09 de janeiro de 2001. Aprova o Plano Nacional de Educação e dá outras providências. Diário Oficial da União, Brasília, DF, p. 1, 10 jan. 2001.

BRASIL. CNE. Resolução CEB nº 01, de 07 de abril de 1999. Define as Diretrizes Curriculares Nacionais para a Educação Infantil. Diário Oficial da União, Brasília, DF, 13 abr. Seção 1, p. 18.

BRASIL. Política Nacional de Educação Infantil: pelo direito das crianças de zero a seis anos à educação. Brasília: MEC/ SEB/DPE/COEDI, 2005.

BRASIL. Parâmetros Nacionais de Qualidade para a Educação Infantil. Brasília: MEC/SEB, 2006.

BRASIL. Secretaria de Educação Fundamental. Referencial curricular nacional para a educação infantil. Brasília, DF: MEC/SEF, 1998.

CANAVIEIRA, Fabiana Oliveira. Por uma política para educação da primeira infância que garanta a interação entre elas: a relação criança-criança nos Indicadores de Qualidade na Educação Infantil. In: FARIA, Ana Lucia Goulart; AQUINO, Ligia Maria Leão. Educação Infantil e PNE: questões e tensões para o século XXI. Campinas: Autores Associados, 2012. p. 31-50.

CORAZZA, Sandra Mara. O currículo e a política cultural da avaliação. Educação e Realidade, Porto Alegre, v. 20, n. 2, p. 47-59, jul./dez. 1995. 
CORAZZA, Sandra Mara. O que quer um currículo? In: CORAZZA, Sandra Mara. O que quer um currículo: pesquisas pós-críticas em educação. Petrópolis, Vozes, 2004. p. 15-26

DEAN, Mitchell. Critical and effective histories: Foucault's methods and historical sociology. London: Routledge, 1997.

FOUCAULT, Michel. A arqueologia do saber. Rio de Janeiro: Forense Universitária, 2007.

FOUCAULT, Michel. A governamentalidade. In: MACHADO, Roberto (Org.). Microfísica do poder. São Paulo: Graal, 2004. p. 277-293.

FOUCAULT, Michel. A ordem do discurso. São Paulo: Loyola, 2005.

FOUCAULT, Michel. Segurança, território e população. São Paulo: Martins Fontes, 2008.

GORDON, Colin. Governmental rationality: an introduction. In.: BURCHEL, Grahan; GORDON, Colin; MILLER, Petter (Ed.). The Foucault effect: studies in governmentality. Chicago: The University of Chicago, 1991. p. 1-50.

KRAMER, Sônia. Subsídios para Diretrizes Curriculares para Educação Básica: Diretrizes Curriculares Nacionais Específicas para Educação Infantil. Trabalho encomendado pelo MEC/SEB. Diretoria de concepções e orientações curriculares da Educação Básica. Brasília: MEC/SEB, 2009.

MARTINS, Lígia Márcia; ARCE, Alessandra. A educação infantil e o ensino fundamental de nove anos. In: ARCE, Alessandra; MARTINS, Lígia Márcia (Orgs.). Quem tem medo de ensinar na Educação Infantil?: em defesa do ato de ensinar. Campinas: Alínea, 2007. p. 37-62.

MINISTÉRIO DA EDUCAÇÃO. Critérios para um atendimento em creches que respeite os direitos fundamentais das crianças. Brasília: MEC/SEF/DPE/COEDI, 1997.

MINISTÉRIO DA EDUCAÇÃO. Política Nacional de Educação Infantil. Brasília: MEC/SEF/DPEF/COEDI, 1994.

MINISTÉRIO DA EDUCAÇÃO. CNE. CEB. Resolução CNE/CEB no 5, de 17 de dezembro de 2009. Fixa as Diretrizes Curriculares Nacionais para a Educação Infantil. Diário Oficial da União, Brasília, DF, 18 dez. 2009. Seção 1, p. 18.

MINISTÉRIO DA EDUCAÇÃO. Secretaria da Educação Básica. Indicadores da Qualidade na Educação Infantil. Brasília: MEC/SEB, 2009.

MINISTÉRIO DA EDUCAÇÃO E DO DESPORTO. Propostas pedagógicas e currículo em Educação Infantil: um diagnóstico e a construção de uma metodologia de análise. Brasília: MEC/SEF/DPEF/COEDI, 1996.
MINISTÉRIO DA EDUCAÇÃO E DO DESPORTO. Subsídios para o Credenciamento e Funcionamento de Instituições de Educação Infantil. Brasília: MEC/SEF, 1998.

Ó, Jorge Ramos do. O governo de si mesmo: modernidade pedagógica e encenações disciplinares do aluno liceal (último quartel do século XIX - meados do século XX). Lisboa: Educa, 2003.

PALAMIDESSI, Mariano. A ordem e o detalhe das coisas ensináveis. 2001. 188 f. Tese (Doutorado em Educação) Programa de Pós-Graduação em Educação, Faculdade de Educação, Universidade Federal do Rio Grande do Sul, 2001.

POPKEWITZ, Thomas. História do currículo, regulação social e poder. In: SILVA, Tomaz Tadeu da (Org.). O sujeito da educação. Estudos Foucaultianos. Petrópolis, RJ: Vozes, 2002. p. 173-210.

PRADO, Alessandra Elisabeth Ferreira Gonçalves; AZEVEDO, Heloisa Helena Oliveira. Currículo para a Educação Infantil: argumentos acadêmicos e propostas de "educação" para crianças de 0 a 5 anos. In: ARCE, Alessandra; JACOMELI, Mara Regina Martins (Org.). Educação Infantil versus Educação Escolar? Entre a (des)escolarização e a precarização do trabalho pedagógico nas salas de aula. Campinas: Autores Associados, 2012. p. 33-52.

ROCHA, Eloisa Acires Candal. A Pedagogia e a Educação Infantil. Revista Brasileira de Educação, Rio de Janeiro, n. 16, p. 27-34, jan./mar. 2001.

SILVA, Tomaz Tadeu. Documentos de identidade: uma introdução às teorias de currículo. Belo Horizonte: Autêntica, 2002.

VEIGA-NETO, Alfredo. A didática e as experiências de sala de aula: uma visão pós-estruturalista. Educação e Realidade, Porto Alegre, v. 21, n. 2, p. 161-176, jul./dez. 1996.

\section{Notas}

\footnotetext{
1 As análises que são apresentadas decorrem de uma pesquisa documental, na qual foram analisados os discursos das Políticas Curriculares de Educação Infantil produzidas a partir da década de 1980,no país. Devido aos limites do artigo, a discussão enfoca somente alguns aspectos das orientações presentes nas Diretrizes Curriculares Nacionais para a Educação Infantil.

2 A definição de tais artigos para análise deve-se ao fato de os mesmos apresentarem a concepção de currículo para a Educação Infantil e os princípios, eixos e objetivos das propostas pedagógicas que devem ser operacionalizadas nas instituições.
}

Artigo recebido em novembro 2013.

Aprovado em julho 2015. 